\title{
Efeito de Adubos Verdes na SupRessão de Espécies de Plantas Daninhas ${ }^{1}$
}

\author{
Effect of Green Fertilizers on the Suppression of Different Species of Weeds
}

\author{
MONQUERO, P.A. ${ }^{2}$, AMARAL, L.R. ${ }^{3}$, INÁCIO, E.M. ${ }^{4}$, BRUNHARA, J.P. ${ }^{4}$, BINHA, D.P. ${ }^{4}$, SILVA, P.V. ${ }^{4}$ \\ e SILVA, A.C. ${ }^{5}$
}

\begin{abstract}
RESUMO - Este trabalho teve como objetivo avaliar o efeito de adubos verdes na supressão de plantas daninhas. O experimento foi instalado no Centro de Ciências Agrárias/UFSCar, localizado no municipio de Araras, São Paulo. O delineamento experimental foi de blocos ao acaso, em esquema fatorial $(3 \times 4 \times 2)$, com quatro repetições, avaliando-se os efeitos de três quantidades de massa verde (40, 50 e 80 t ha $\left.^{-1}\right)$ das espécies Crotalariajuncea, Canavalia ensiformis, Mucuna aterrima e Pennisetum glaucum, sob dois tipos de manejo (dispostas na superfície e incorporadas ao solo), na emergência e biomassa seca de duas espécies de plantas daninhas (Ipomoea grandifolia e Brachiaria decumbens). Adicionalmente, foram avaliadas testemunhas sem cobertura vegetal e amostras de solo coletadas de área com alta infestação de Panicum maximum. As avaliações foram feitas até os 30 dias após semeadura, determinando-se as plantas daninhas emergidas e a biomassa seca. M. aterrima foi a espécie mais eficiente na redução da germinação de I. grandifolia em todos os manejos utilizados. Para a espécie E. heterophylla, destacaram-se os tratamentos com P. glaucum e M. aterrima, principalmente quando se utilizaram $80 \mathrm{t} \mathrm{ha}^{-1}$ de biomassa, independentemente da forma de manejo. Para B. decumbens e P. maximum, as espécies $P$. glaucum e $C$. juncea foram as mais eficientes na redução da germinação.
\end{abstract}

Palavras-chave: adubos verdes, cobertura morta, resíduos vegetais, plantas daninhas.

\begin{abstract}
This work aimed to study the effect of green fertilizers on the suppression of some weed species. The experiment was installed at the Agrarian Sciences / UFSCar Center, located in

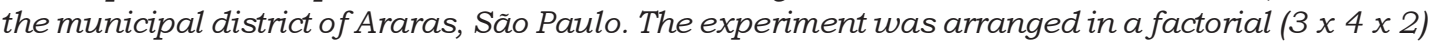
design with four repetitions to evaluate the effect of three amounts of green mass 140,50 and $80 \mathrm{tha}^{-1}$ ) of the species Crotalaria juncea, Canavalia ensiformis, Mucuna aterrima and Pennisetum glaucum, under two types of handling (on the surface and soil incorporated) at the emergence and dry biomass of two species of the weeds (Ipomoea grandifolia and Brachiaria decumbens). Additionally, controls without vegetal covering and soil samples collected from the area with high infestation of $\boldsymbol{P}$. maximum were evaluated. The evaluations were carried out up to 30 days after sowing, and the emerged weeds and dry biomass were determined. M. aterrima was the most efficient in reducing I. grandifolia. For $\boldsymbol{E}$. heterophylla, the best treatments were those using P. glaucum and $\boldsymbol{M}$. aterrima, mainly when $80 t \mathrm{th}^{-1}$ of biomass was applied. For $\boldsymbol{B}$. decumbens and $\boldsymbol{P}$. maximum, the species $\boldsymbol{P}$. glaucum and $\mathbf{C}$. juncea were the most efficient in reducing germination.
\end{abstract}

Keywords: green fertilizers, mulching, vegetal residues, weeds.

1 Recebido para publicação em 9.6.2008 e na forma revisada em 18.2.2009.

2 Professora Adjunta, Centro de Ciências Agrárias/UFSCar, <pamonque@ cca.ufscar.br>; ${ }^{3}$ Aluno de graduação no CCA/UFSCar e bolsista FAPESP; ${ }^{4}$ Alunos de graduação no CCA/UFSCar; ${ }^{5}$ Pesquisadora no APTA/Polo Regional da Alta Sorocabana. 


\section{INTRODUÇÃO}

Os efeitos da cobertura morta sobre as plantas daninhas devem ser analisados sob três aspectos distintos - físico, químico e biológico -, embora haja interações entre eles (Pitelli \& Pitelli, 2004).

$\mathrm{O}$ efeito físico da cobertura morta pode interferir na germinação e na taxa de sobrevivência das plântulas de algumas espécies de plantas daninhas. Nos efeitos sobre o processo germinativo, pode ocorrer a redução da germinação de sementes fotoblásticas positivas, as quais requerem determinado comprimento de onda para germinar, e a redução da germinação de sementes que necessitam de grande amplitude térmica para iniciar o processo germinativo. Sementes da espécie de planta daninha erva-de-touro (Tridax procumbens) são fotoblásticas positivas, portanto não germinam sem a presença de luz (Guimarães et al., 2002).

O efeito físico da cobertura morta também reduz as chances de sobrevivência das plântulas das espécies com pequena quantidade de reservas nos diásporos. Muitas vezes, as reservas não são suficientes para garantir a sobrevivência da plântula no espaço percorrido dentro da cobertura morta até que tenha acesso à luz e inicie o processo fotossintético.

Quantidades de palha de cana-de-açúcar iguais ou superiores a $6 \mathrm{tha}^{-1}$ diminuiram a agressividade de Sida rhombifolia, enquanto as espécies invasoras Bidens pilosa, Euphorbia heterophylla e Ipomoea grandifolia mantiveram-se resistentes com a quantidade de palha até $15 \mathrm{t} \mathrm{ha}^{-1}$ (Martins et al.,1999).

A cobertura morta do solo com palha de sorgo reduziu linearmente as infestações de $B$. plantaginea e $S$. rhombifolia, e a presença de resíduos da parte aérea do sorgo e do milheto é mais importante na supressão das plantas daninhas do que a presença de resíduos das raízes dessas culturas (Trezzi \& Vidal, 2004).

A fitomassa de Arachis pintoi, Crotalaria juncea e Cajanus cajan incorporada ou na superficie reduziu significantemente as populações das plantas daninhas Brachiaria decumbens, Panicum maximum e Bidens pilosa (Severino \& Christoffoleti, 2001).
As espécies C. spectabilis, S. bicolor, C. ochroleuca, $M$. aterrima e $M$. pruriens reduziram significativamente a infestação e o peso da matéria seca das plantas daninhas $D$. horizontalis, H. lophanta e A. Spinosus, enquanto a espécie $P$. glaucum mostrou-se menos eficiente nesse efeito (Erasmo et al., 2004).

Quanto aos efeitos biológicos, verificou-se que a deposição de resíduos orgânicos sobre o solo e o consequente aumento do teor de matéria orgânica, associado a uma menor vulnerabilidade dos microrganismos nesse sistema, criam condições para instalação de uma densa e diversificada microbiocenose na camada superficial do solo. Na composição específica dessa microbiocenose há grande quantidade de organismos que podem utilizar sementes e plântulas de plantas daninhas como fontes de energia. De maneira geral, os microrganismos exercem importantes funções na deterioração e perda de viabilidade dos diversos tipos de propágulos no solo (Pitelli \& Durigan, 2001). A cobertura morta cria também um abrigo seguro para alguns inimigos naturais, como roedores, insetos e outros pequenos animais que são predadores de sementes e plântulas das espécies de plantas daninhas.

Em relação aos efeitos químicos, a cobertura morta pode ter influência alelopática sobre as plantas daninhas. A alelopatia consiste na liberação de substâncias químicas no ambiente por um dado organismo, as quais irão interagir com outros, inibindo ou estimulando o seu crescimento e desenvolvimento (Rice, 1984). Essa influência pode ocorrer entre microrganismos, entre microrganismos e plantas, entre plantas cultivadas, entre plantas daninhas, e entre plantas daninhas e plantas cultivadas.

Diversas plantas produzem substâncias químicas com propriedades alelopáticas, como os glicosídeos cianogênicos (Souza, 1988), ácidos fenólicos, agropireno, cumarinas (Silva, 1978) e flavonoides (Rice, 1984). Essas substâncias são distribuídas em concentrações variadas nas diferentes partes da planta e durante o seu ciclo de vida. Quando essas substâncias são liberadas em quantidades suficientes, causam efeitos alelopáticos, que podem ser 
observados na germinação, no crescimento e/ou no desenvolvimento de plantas já estabelecidas e, ainda, no desenvolvimento de microrganismos (Silva, 1978; Carvalho, 1993).

Os compostos alelopáticos podem ser liberados das plantas por lixiviação a partir dos tecidos, volatilização pelas folhas, exsudação pelas raízes e decomposição de resíduos da planta (Souza, 1988; Rodrigues et al., 1993; Weidenhamer, 1996).

A atividade alelopática da cobertura morta sobre as plantas daninhas depende diretamente da qualidade e da quantidade do material vegetal depositado na superficie, do tipo de solo, da população microbiana, das condições climáticas e da composição de espécies da comunidade de plantas daninhas de forma específica.

Os sintomas dos efeitos alelopáticos provocados pelas coberturas mortas nas culturas são a inibição da germinação, a falta de vigor vegetativo ou morte de plântulas, o amarelecimento ou clorose das folhas, a redução do perfilhamento e o atrofiamento ou deformação das raízes (Almeida, 1985).

Efeitos alelopáticos de algumas gramíneas e leguminosas foram verificados por Medeiros et al. (1990), cujas espécies, como aveia (Avena sativa), azevém (Lolium multiflorum) e Vicia sp., podem ser utilizadas como culturas de cobertura com propriedades alelopáticas.

O eficiente controle de plantas daninhas pelo feijão-de-porco (Canavalia ensiformis) é atribuído a efeito alelopático (Burle et al., 2006). Observou-se efeito alelopático, de maneira diferencial, de extratos hidroalcoólicos de parte das raízes, sementes e extratos brutos de sementes de $C$. ensiformis sobre as plantas daninhas Mimosa pudica, Urena lobata, Senna obtusifolia e Senna occidentalis (Souza Filho, 2002).

Foi constatado efeito da alelopatia no declínio de leguminosas em pastagens cuja produção da leguminosa forrageira Trifolium subterraneum foi reduzida na presença de resíduos das gramineas Phalaris aquatica e Triticum aestivum. Quando os resíduos foram incorporados ao solo, esse efeito não foi evidenciado (Leigh et al., 1995).

A Crotalaria juncea tem efeito alelopático na supressão de plantas daninhas com bastante expressividade (Calegari et al., 1993). Exemplos de efeitos alelopáticos de leguminosas sobre a tiririca (Cyperus rotundus) foram constatados pelos niveis de controle das espécies Mucuna aterrima e Crotalaria juncea (Wutke, 1993; Pereira \& Silva, 1989).

A aveia-preta (Avena strigosa) também contribui para o controle de plantas daninhas por meio da alelopatia causada pela excreção de substâncias que inibem a germinação das sementes (Pitol, 1986).

Apesar de diversos trabalhos sobre o efeito da cobertura morta, existe a necessidade de incrementar pesquisas em diferentes niveis para entender o efeito supressor de determinadas plantas daninhas pela cobertura vegetal, sobretudo com relação às espécies e no manejo de adubos verdes.

O objetivo deste trabalho foi avaliar os efeitos de diferentes quantidades de palha dos adubos verdes Crotalaria juncea, Canavalia ensiformis, Mucuna aterrima e Pennisetum glaucum, dispostas na superficie ou incorporadas no solo, sobre a emergência e biomassa seca das espécies de plantas daninhas Ipomoea grandifolia, Brachiaria decumbens e Panicum maximum.

\section{MATERIAL E MÉTODOS}

O experimento foi instalado em casa de vegetação no Centro de Ciências Agrárias/ UFSCar, localizado no município de Araras-SP. O clima, pela classificação de Köppen, é do tipo Cwa, mesotérmico, com verões quentes e úmidos e invernos secos.

As sementes das plantas daninhas foram adquiridas em empresa especializada, com as seguintes recomendações: I. grandifolia (0,26 g de sementes para obter 20 plantas) e $B$. decumbens $(0,30 \mathrm{~g}$ de sementes para obter 20 plantas). Para obtenção do material vegetal ou palha a ser colocado nos vasos, os adubos verdes foram semeados no campo, em canteiros com $2 \times 15 \mathrm{~m}$, durante os meses de outubro a novembro, de acordo com as características de cada espécie (Piraí, 2008). O espaçamento e a densidade de sementes por metro linear foram os recomendados para cada cultura de cobertura; as plantas foram mantidas no campo até o início do florescimento. 
Foi utilizado solo de um Latossolo Vermelho distrófico, sendo coletadas amostras da camadaarável. Análises química e física do solo foram feitas pelo Laboratório de Recursos Naturais e Proteção Ambiental/CCA-UFSCar (Tabela 1). O solo coletado foi submetido à solarização, de acordo com a metodologia proposta por Sinigaglia (2002). Coletou-se também solo de área com alta infestação de Panicum maximum, a fim de se comparar o efeito dos tratamentos sobre a emergência desta planta daninha, em cuja amostra não foi realizada a solarização.

Cada unidade experimental foi constituída por um vaso plástico com capacidade de 15 litros de solo. O delineamento experimental utilizado foi de blocos ao acaso, tendo fatorial $(3 \times 4 \times 2)$ com quatro repetições, constando os tratamentos de três quantidades $(40,50$ e $80 \mathrm{t} \mathrm{ha}^{-1}$ ) de massa verde das espécies Crotalaria juncea, Canavalia ensiformis, Mucuna aterrima e Pennisetum glaucum, sob dois tipos de manejo (dispostas na superficie ou incorporadas a $5 \mathrm{~cm}$ ). Avaliaram-se os efeitos sobre a emergência e a biomassa seca das espécies de plantas daninhas Ipomoea grandifolia e Brachiaria decumbens. Adicionalmente, foram avaliadas testemunhas em solo sem cobertura vegetal e solo com alta infestação de $P$. maximum (50 plantas $\mathrm{m}^{-2}$ ), coletado de área em pousio.

Os vasos foram preenchidos com solo coletado da camada superficial de $5 \mathrm{~cm}$, que foi misturado às sementes de cada espécie de planta daninha com a quantidade de sementes, para obtenção de 20 plantas. Em seguida, foi depositada na superficie do vaso a massa verde das partes aéreas dos adubos verdes, previamente trituradas. Nos tratamentos com incorporação, foi realizada a homogeneização da massa verde triturada das leguminosas com o solo.

As avaliações das plantas daninhas foram feitas de acordo com metodologia proposta por
Correia \& Durigan (2004), em que o número de plantas emergidas foi obtido aos 7, 14, 21 e 28 dias após semeadura (DAS). Foram consideradas emersas as plântulas com mais de $0,5 \mathrm{~cm}$ de altura. Aos 28 DAS, as plantas foram cortadas rente ao solo, com sua parte aérea sendo acondicionada em sacos de papel e levada à estufa com circulação forçada de ar a $60{ }^{\circ} \mathrm{C}$, até atingirem peso constante, para em seguida, após a pesagem, se obter o peso da matéria seca.

Os dados foram submetidos à análise de variância e, quando significativos, as médias foram comparadas pelo teste Tukey a $5 \%$ de probabilidade.

\section{RESULTADOS E DISCUSSÃO}

\section{C. ensiformis}

Considerando o número de plantas daninhas que emergiram nos tratamentos sob efeito da biomassa verde de C. ensiformis, observou-se que para I. grandifolia houve diferença significativa em relação à testemunha; o uso de $80 \mathrm{t} \mathrm{ha}^{-1}$ de biomassa na superfície do solo foi o mais eficiente na supressão desta planta daninha (Tabela 2). Essa tendência é acompanhada pela redução da biomassa seca da planta daninha, que foi mais drástica nos tratamentos envolvendo $80 \mathrm{t} \mathrm{ha}^{-1}$ de biomassa de C. ensiformis. Somente nesta quantidade de biomassa verificou-se diferença entre a incorporação ou não, observando-se maior supressão sobre esta espécie daninha quando não houve encorporação (Figura 1).

No tratamento com $80 \mathrm{t} \mathrm{ha}^{-1}$ incorporado, verificou-se intensa clorose das plantas e algumas folhas com pontos necróticos nas suas margens, indicando um possivel efeito alelopático ocasionado pela decomposição dos resíduos vegetais de $C$. ensiformis incorporados ao solo.

Tabela 1 - Características físico-químicas do solo utilizado

\begin{tabular}{|c|c|c|c|c|c|c|c|c|c|c|c|c|c|}
\hline \multirow{2}{*}{ Amostra } & $\mathrm{pH}$ & $\mathrm{MO}$ & $\mathrm{P}$ & $\mathrm{K}$ & $\mathrm{Ca}$ & $\mathrm{Mg}$ & $\mathrm{Al}$ & SB & CTC & \multirow{2}{*}{$\begin{array}{l}\mathrm{V} \% \\
(\%) \\
\end{array}$} & Argila & Silte & Areia \\
\hline & $\left(\mathrm{CaCl}_{2}\right)$ & $\left(\mathrm{g} \mathrm{dm}^{-3}\right)$ & $\left(\mathrm{mg} \mathrm{dm}^{-3}\right)$ & \multicolumn{6}{|c|}{$\left(\mathrm{mmol}_{\mathrm{c}} \mathrm{dm}^{-3}\right)$} & & \multicolumn{3}{|c|}{$\left(\mathrm{g} \mathrm{kg}^{-1}\right)$} \\
\hline LV & 5,3 & 25 & 5,3 & 3,7 & 31 & 14 & 1,6 & 48,7 & 72,7 & 67 & 530 & 320 & 150 \\
\hline
\end{tabular}


Tabela 2 - Número de plantas de I. grandifolia, B. decumbens e $P$. maximum nos tratamentos com diferentes quantidades de palha e manejo de Canavalia ensiformis

\begin{tabular}{|l|c|c|c|}
\hline \multicolumn{1}{|c|}{ Tratamento } & \multicolumn{3}{|c|}{ Número total de plantas daninhas emersas } \\
\hline $\begin{array}{c}\text { Quantidade de } \\
\text { biomassa e manejo }\end{array}$ & I. grandifolia & B. decumbens & P. maximum \\
\hline $40 \mathrm{t} \mathrm{ha}^{-1}$ superficial & $7,25 \mathrm{~b}$ & $10,0 \mathrm{~b}$ & $147,0 \mathrm{~d}$ \\
\hline $40 \mathrm{t} \mathrm{ha}^{-1}$ incorporada & $6,25 \mathrm{~b}$ & $8,0 \mathrm{c}$ & $173,0 \mathrm{bc}$ \\
\hline $50 \mathrm{t} \mathrm{ha}^{-1}$ superficial & $7,0 \mathrm{~b}$ & $8,25 \mathrm{c}$ & $165,0 \mathrm{~cd}$ \\
\hline $50 \mathrm{t} \mathrm{ha}^{-1}$ incorporada & $7,0 \mathrm{~b}$ & $6,0 \mathrm{~d}$ & $190,0 \mathrm{~b}$ \\
\hline $80 \mathrm{t} \mathrm{ha}^{-1}$ superficial & $2,50 \mathrm{c}$ & $1,0 \mathrm{f}$ & $50,0 \mathrm{f}$ \\
\hline $80 \mathrm{t} \mathrm{ha}^{-1}$ incorporada & $6,75 \mathrm{~b}$ & $4,0 \mathrm{e}$ & $95,0 \mathrm{e}$ \\
\hline Testemunha & $9,0 \mathrm{a}$ & $19,0 \mathrm{a}$ & $220,0 \mathrm{a}$ \\
\hline CV & 7,65 & 2,35 & 5,37 \\
\hline DMS 5\% & 1,15 & 0,43 & 18,34 \\
\hline
\end{tabular}

Médias seguidas por letras iguais na coluna não diferem significativamente entre si pelo teste de Tukey a $5 \%$.

Para B. decumbens, os tratamentos mais eficazes na redução de plantas emergidas foram $80 \mathrm{t} \mathrm{ha}^{-1}$ da biomassa depositada superficialmente, seguido por $80 \mathrm{t} \mathrm{ha}^{-1}$ desta biomassa incorporada.

Constatou-se efeito da leguminosa sobre a germinação de $P$. maximum, principalmente nas maiores quantidades de biomassa de
$80 \mathrm{t} \mathrm{ha}^{-1}$, destacando-se a deposição superficial dos resíduos vegetais, que apresentaram maior inibição da emergência desta espécie daninha. Assim, o uso de C. ensiformis pode reduzir com o tempo o banco de sementes desta espécie daninha. Um aspecto que pode ter contribuído para a inibição mais expressiva da emergência de $P$. maximum é o efeito físico da palha, uma vez que as sementes desta espécie possuem tamanho muito reduzido.

Observou-se redução de biomassa de I. grandifolia em todos os tratamentos em relação à testemunha (Figura 1). Embora não tenha sido constatado a diferença estatística entre a testemunha e os tratamentos, $B$. decumbens mostrou redução da biomassa nos tratamentos com palha na superfície, à exceção do tratamento com maior quantidade de palha, o que pode ser atribuído a efeito alelopático decorrente da incorporação. Panicum maximum apresentou maior biomassa nos tratamentos com palha na superficie, o que pode ser atribuído à menor competição intraespecífica, visto que emergiram menos plantas nesses tratamentos.

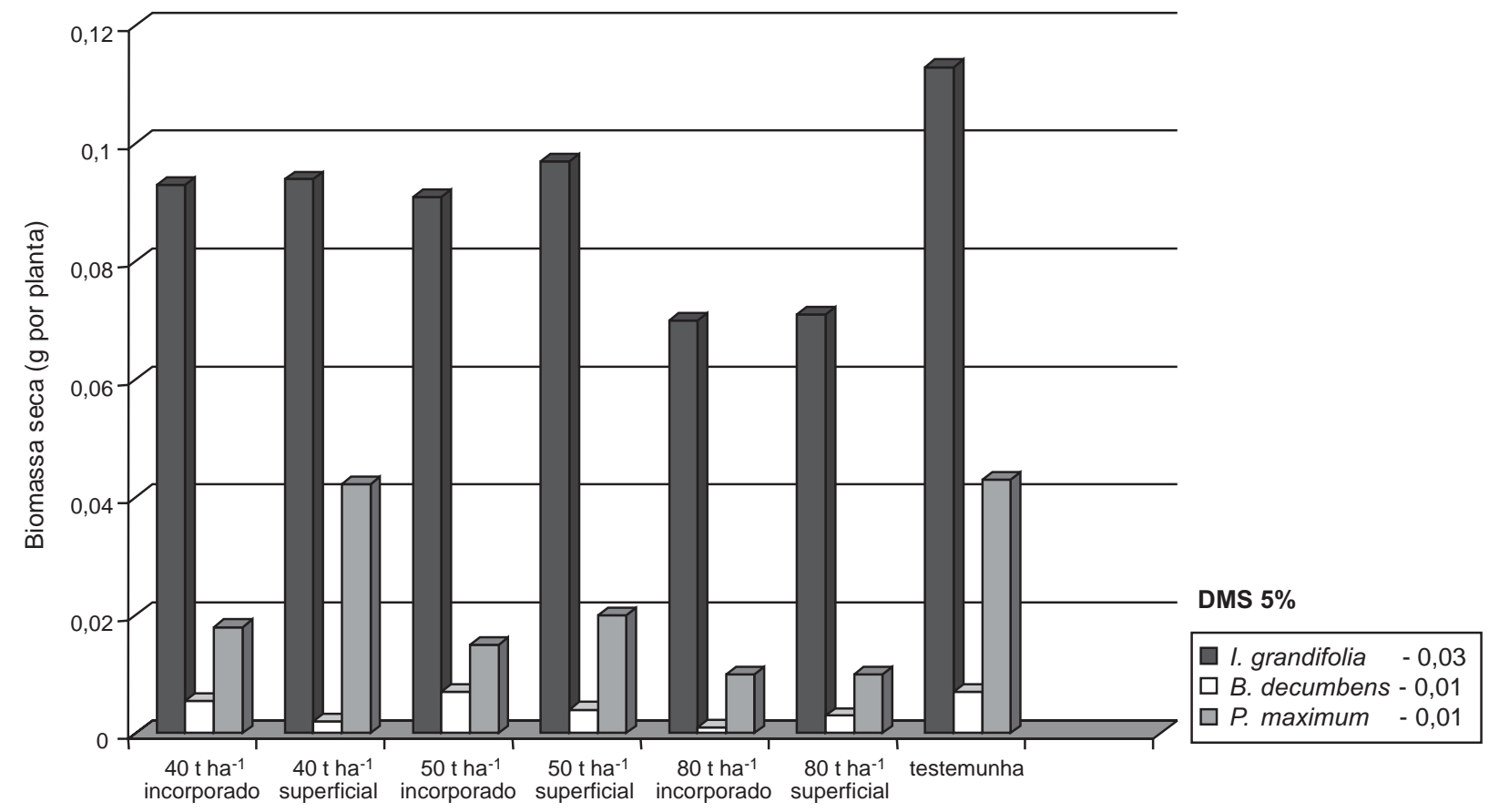

Figura 1 - Biomassa seca (g por planta) das plantas daninhas em diferentes tratamentos com palha de Canavalia ensiformis. 
Coberturas verdes do solo, tendo como exemplo a leguminosa Canavalia ensiformis, são culturas geralmente muito competitivas com as plantas daninhas. O objetivo principal dessas coberturas é a melhoria das propriedades físicas, químicas e biológicas do solo; entretanto, muitas dessas plantas possuem grande poder inibitório sobre determinadas plantas daninhas mesmo após o corte e formação de uma cobertura morta sobre o solo (Gomes \& Leal, 2003).

\section{M. aterrima}

O uso do adubo verde $M$. aterrima reduziu de maneira significativa o número de plantas daninhas I. grandifolia e P. maximum (Tabela 3). No caso de I. grandifolia, os tratamentos mais eficientes foram os que envolveram maior quantidade de biomassa de $80 \mathrm{t} \mathrm{ha}^{-1}$ dessa leguminosa, independentemente da forma do manejo de aplicação - com incorporação ou disposta na superficial. Todavia, maior redução da biomassa seca desta espécie daninha ocorreu quando a massa verde da leguminosa foi incorporada ao solo (Figura 2). Além disso, observou-se amarelecimento e estiolamento das plantas emergidas no tratamento com 80 tha $^{-1}$ superficial, indicando uma dificuldade desta espécie em transpor a barreira física ocasionada pelos resíduos vegetais de $M$. aterrima.

Para B. decumbens, o efeito sobre a germinação foi menos pronunciado, destacandose, entretanto, o tratamento com $80 \mathrm{t} \mathrm{ha}^{-1} \mathrm{de}$ biomassa incorporada, que reduziu completamente a germinação dessa espécie daninha. Com 40 e $50 \mathrm{t} \mathrm{ha}^{-1}$ de biomassa na superficie,

Tabela 3 - Número de plantas de I. grandifolia, B. decumbens e $P$. maximum nos tratamentos com diferentes quantidades de palha e manejo de Mucuna aterrima

\begin{tabular}{|l|c|c|c|}
\hline \multicolumn{1}{|c|}{ Tratamento } & \multicolumn{3}{|c|}{ Número total de plantas daninhas emersas } \\
\hline $\begin{array}{c}\text { Quantidade de } \\
\text { biomassa e manejo }\end{array}$ & I. grandifolia & B. decumbens & P. maximum \\
\hline $40 \mathrm{t} \mathrm{ha}^{-1}$ superficial & $6,00 \mathrm{~b}$ & $3,00 \mathrm{~b}$ & $95,00 \mathrm{~b}$ \\
\hline $40 \mathrm{t} \mathrm{ha}^{-1}$ incorporada & $3,00 \mathrm{~cd}$ & $6,00 \mathrm{a}$ & $84,00 \mathrm{c}$ \\
\hline $50 \mathrm{t} \mathrm{ha}^{-1}$ superficial & $3,25 \mathrm{~cd}$ & $2,00 \mathrm{~b}$ & $48,00 \mathrm{~d}$ \\
\hline $50 \mathrm{t} \mathrm{ha}^{-1}$ incorporada & $4,00 \mathrm{c}$ & $6,00 \mathrm{a}$ & $54,00 \mathrm{~d}$ \\
\hline $80 \mathrm{t} \mathrm{ha}^{-1}$ superficial & $1,25 \mathrm{~d}$ & $3,00 \mathrm{~b}$ & $20,00 \mathrm{e}$ \\
\hline $80 \mathrm{t} \mathrm{ha}^{-1}$ incorporada & $1,25 \mathrm{~d}$ & $0,00 \mathrm{c}$ & $44,00 \mathrm{~d}$ \\
\hline Testemunha & $8,50 \mathrm{a}$ & $7,00 \mathrm{a}$ & $138,00 \mathrm{a}$ \\
\hline CV & 23,28 & 16,62 & 6,50 \\
\hline DMS 5\% & 2,08 & 1,42 & 10,31 \\
\hline
\end{tabular}

Médias seguidas por letras iguais na coluna não diferem significativamente entre si pelo teste de Tukey a $5 \%$.

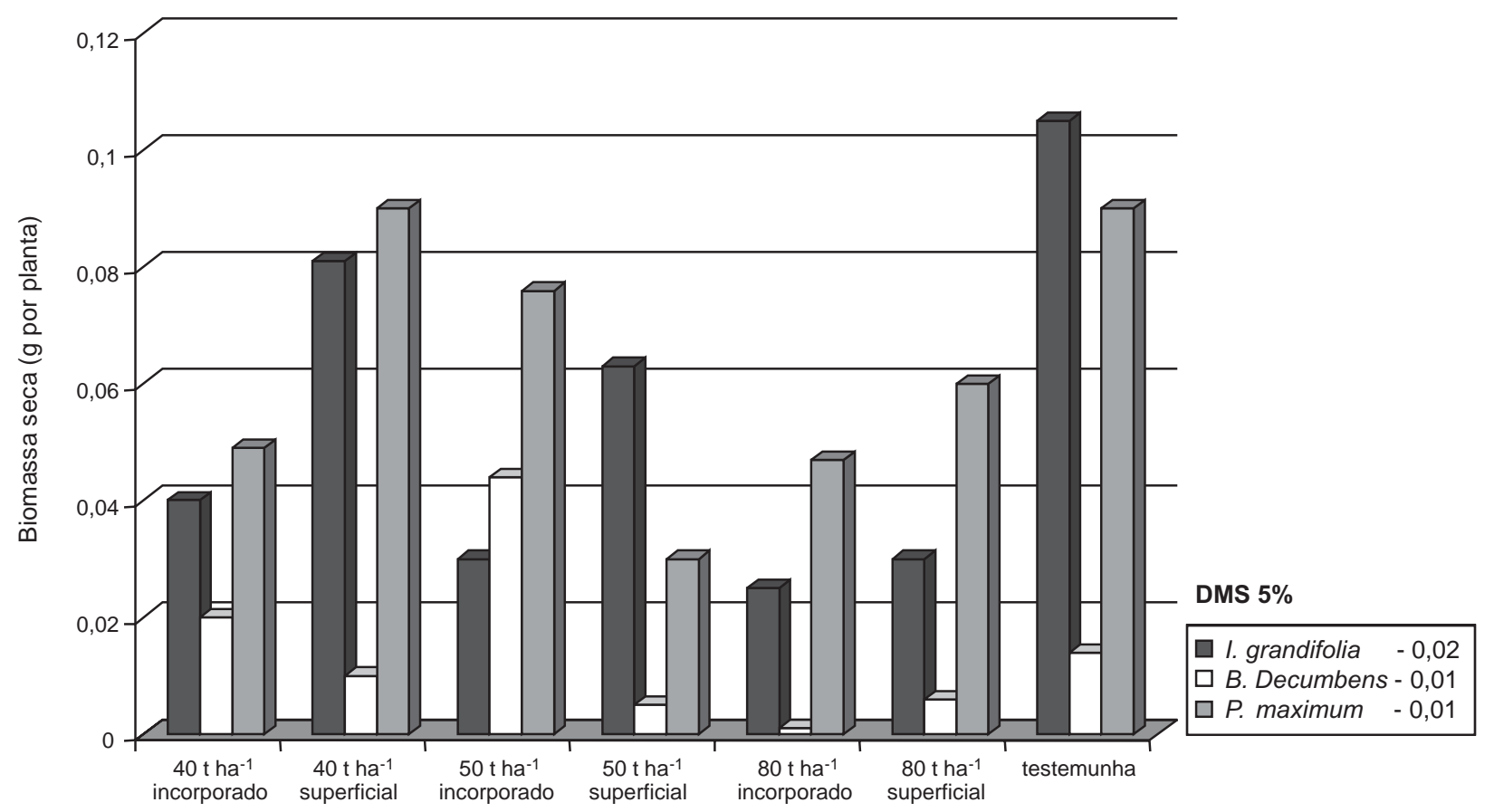

Figura 2 - Biomassa seca (g por planta) das plantas daninhas em diferentes tratamentos com palha de Mucuna aterrima. 
houve maior controle da espécie em relação à incorporação desse material. Constatou-se influência do intervalo de tempo entre a incorporação e a semeadura, na fitotoxicidade provocada por material vegetal sobre as culturas (Abboud \& Duque, 1986). Quando se semeou feijão logo após a incorporação de mucunapreta no terreno, a cultura apresentou sintomatologia de queima generalizada das folhas e redução de produção, o que se agravou em períodos de escassez de chuvas.

Para P. maximum, observou-se que o uso de maior quantidade de biomassa da leguminosa proporcionou maiores reduções no número de plantas, somente no tratamento com 80 t ha $^{-1}$ superficial, bem como da biomassa seca dessa planta daninha. De modo geral, não houve uma tendência em relação à incorporação da massa verde da leguminosa sobre a biomassa seca ou emergência desta planta daninha, sendo essas variáveis alteradas de acordo com a quantidade de palha, o que evidencia a complexidade dos efeitos envolvidos.

O extrato aquoso da parte aérea da mucunapreta proporcionou redução no crescimento, estabilização na multiplicação de tubérculos e menor índice de velocidade de emergência da tiririca (Cyperus rotundus), caracterizando efeito alelopático (Carvalho et al., 2002). Contudo, o extrato aquoso da parte aérea do feijão-deporco estimulou o crescimento da tiririca, caracterizando efeito alelopático benéfico.

\section{C. juncea}

A biomassa de 40 e 50 t ha $^{-1}$ de $C$. juncea incorporada ao solo mostrou-se ineficaz no controle de I. grandifolia, igualando-se à testemunha (Tabela 4). Em quantidade menor de massa verde de leguminosa, a melhor opção de manejo é deixá-las na superfície do solo. Para esta espécie daninha, houve menor emergência e menor produção de biomassa seca com o uso de $80 \mathrm{t} \mathrm{ha}^{-1}$ de massa verde de C. juncea, independentemente da forma de manejo (Figura 3). Com essa quantidade de biomassa observaram-se plantas mais debilitadas, apresentando amarelecimento, necrose e deformação de folhas, devido a prováveis efeitos físicos e/ou químicos.

$B$. decumbens mostrou-se bastante suscetível; todos os tratamentos reduziram de
Tabela 4 - Número de plantas de I. grandifolia, B. decumbens e $P$. maximum nos tratamentos com diferentes quantidades de palha e manejo de Crotalaria juncea

\begin{tabular}{|l|c|c|c|}
\hline \multicolumn{1}{|c|}{ Tratamento } & \multicolumn{3}{|c|}{ Número total de plantas daninhas emersas } \\
\hline $\begin{array}{c}\text { Quantidade de } \\
\text { biomassa e manejo }\end{array}$ & I. grandifolia & B. decumbens & P. maximum \\
\hline $40 \mathrm{t} \mathrm{ha}^{-1}$ superficial & $6,25 \mathrm{~b}$ & $0,25 \mathrm{~d}$ & $82,00 \mathrm{~b}$ \\
\hline $40 \mathrm{t} \mathrm{ha}^{-1}$ incorporada & $14,00 \mathrm{a}$ & $5,25 \mathrm{~b}$ & $57,00 \mathrm{c}$ \\
\hline $50 \mathrm{t} \mathrm{ha}^{-1}$ superficial & $4,75 \mathrm{bc}$ & $0,75 \mathrm{~d}$ & $52,00 \mathrm{c}$ \\
\hline $50 \mathrm{t} \mathrm{ha}^{-1}$ incorporada & $12,00 \mathrm{a}$ & $2,25 \mathrm{c}$ & $66,00 \mathrm{c}$ \\
\hline $80 \mathrm{t} \mathrm{ha}^{-1}$ superficial & $2,00 \mathrm{c}$ & $0,25 \mathrm{~d}$ & $6,25 \mathrm{~d}$ \\
\hline $80 \mathrm{t} \mathrm{ha}^{-1}$ incorporada & $3,25 \mathrm{c}$ & $0,50 \mathrm{~d}$ & $9,50 \mathrm{~d}$ \\
\hline Testemunha & $15,00 \mathrm{a}$ & $19,00 \mathrm{a}$ & $220,00 \mathrm{a}$ \\
\hline CV & 20,31 & 14,00 & 9,02 \\
\hline DMS 5\% & 3,98 & 1,30 & 14,59 \\
\hline
\end{tabular}

Médias seguidas por letras iguais na coluna não diferem significativamente entre si pelo teste de Tukey a $5 \%$.

maneira drástica a emergência desta planta daninha, sendo o manejo mais eficiente deixar os resíduos vegetais dos adubos verdes sobre o solo, propiciando menor emergência desta espécie. A biomassa de $B$. decumbens também foi reduzida pelos tratamentos, à exceção do tratamento com $40 \mathrm{t} \mathrm{ha}^{-1}$ de palha, em que se verificou acúmulo semelhante ao da testemunha (Figura 3). No caso de P. maximum, também se observou redução no número de plantas e na biomassa seca, sendo o tratamento mais eficiente o uso de $80 \mathrm{t} \mathrm{ha}^{-1}$, independentemente da forma de manejo (Tabela 4 e Figura 3).

A fitomassa dos adubos verdes Arachis pintoi, C. juncea e Cajanus cajan, tanto incorporada como depositada na superficie do solo, reduziu significativamente as populações das plantas daninhas $B$. decumbens, $P$. maximum e $B$. pilosa. Observou-se, também, que as correlações ocorreram de maneira distinta pelos diferentes adubos verdes, sendo $C$. cajan, de forma geral, o mais efetivo na supressão das plantas daninhas estudadas (Severino \& Christoffoleti, 2001).

\section{P. glaucum}

Todos os tratamentos com P. glaucum, tanto incorporado como depositado sobre o solo, mostraram redução na emergência de a I. grandifolia (Tabela 5). Apesar de não ser observada diferença entre os materiais verdes das leguminosas dispostos na superficie ou incorporados no tocante ao efeito na 


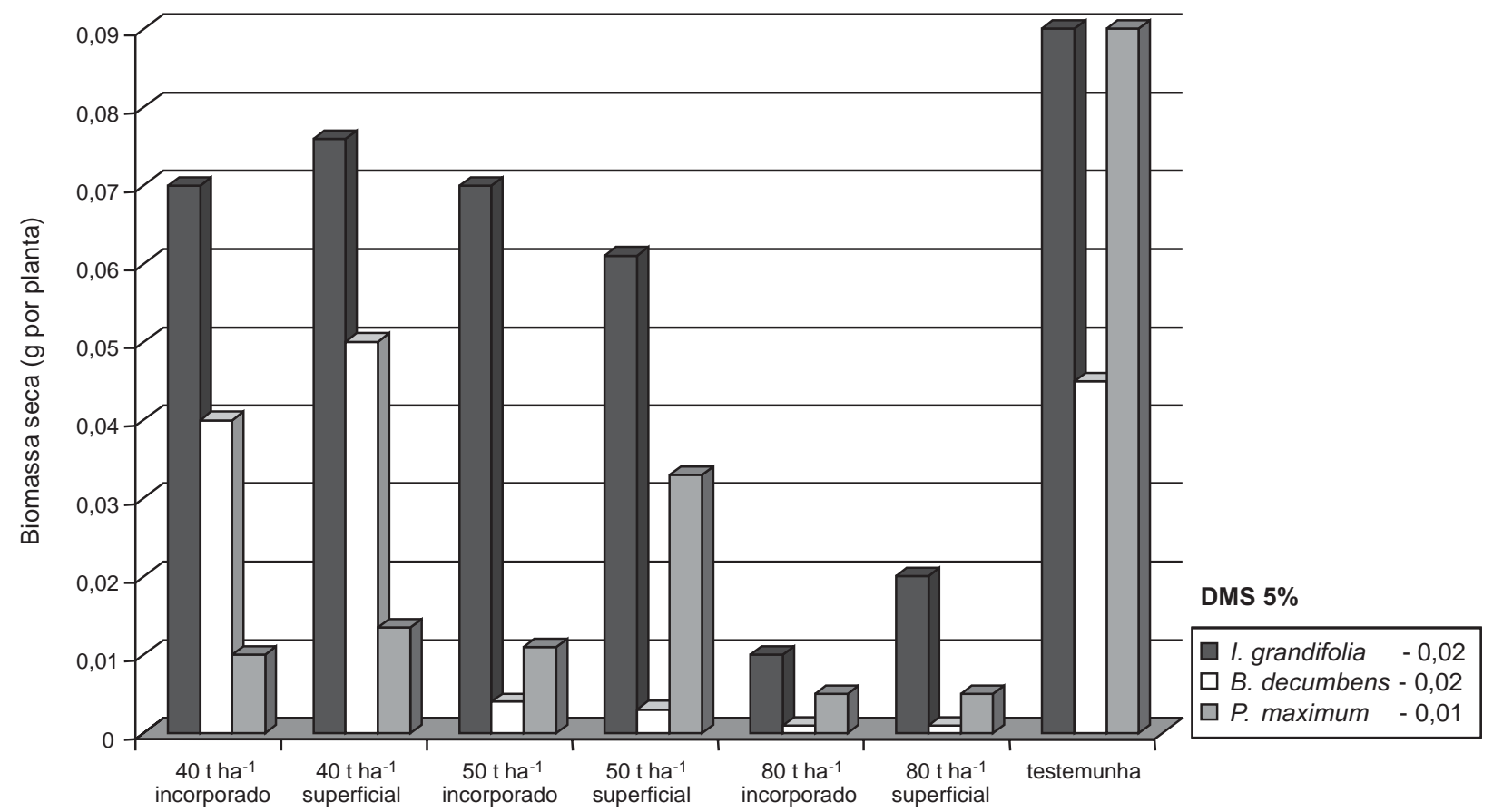

Figura 3 - Biomassa seca (g por planta) das plantas daninhas em diferentes tratamentos com palha de Crotalaria juncea.

emergência dessa espécie daninha, a biomassa seca de I. grandifolia foi expressivamente maior nos tratamentos em que houve incorporação de $P$. glaucum (Figura 4).

Efeito semelhante foi observado para $B$. decumbens em relação à emergência das plantas (Tabela 5); todavia, para biomassa, apesar de reduzida em relação à testemunha, não se evidenciou tendência em relação ao manejo incorporado ou superficial (Figura 4).

$P$. maximum também foi suprimido pela presença da palha de $P$. glaucum, principalmente com o uso de 50 e $80 \mathrm{t} \mathrm{ha}^{-1}$ de palha incorporada ao solo, com reduções de 87 e $92 \%$ da germinação, respectivamente (Tabela 5). A massa seca dessa espécie foi expressivamente menor, em todas as quantidades de palha, quando não houve incorporação da biomassa de $P$. glaucum, comparando-se ao tratamento com incorporação (Figura 4).

Dessa forma, confirma-se a destacada capacidade de supressão de plantas daninhas pela cultura do milheto ( $P$. glaucum). Verificarmse reduções médias de 91,96 e $59 \%$ da infestação de Brachiaria plantaginea, Sida rhombifolia e Bidens pilosa, respectivamente, em áreas cobertas com palha de milheto
(Trezzi \& Vidal, 2004). Contudo, algumas espécies de plantas daninhas dicotiledôneas são fortes competidoras com o milheto, necessitando ser controladas para o bom crescimento e desenvolvimento dessa cultura (Erasmo et al., 2004). Sem o controle das plantas daninhas durante o período crítico de sua competição com milheto, que vai até sete semanas após a emergência das plantas, pode-se reduzir a produtividade de grãos em até $36 \%$ (Carson, 1987).

Tabela 5 - Número de plantas de I. grandifolia, B. decumbens e $P$. maximum nos tratamentos com diferentes quantidades de palha e manejo de Pennisetum glaucum

\begin{tabular}{|l|c|c|c|}
\hline \multicolumn{1}{|c|}{ Tratamento } & \multicolumn{3}{|c|}{ Número total de plantas daninhas emersas } \\
\hline $\begin{array}{c}\text { Quantidade de } \\
\text { biomassa e manejo }\end{array}$ & I. grandifolia & B. decumbens & P. maximum \\
\hline $40 \mathrm{t} \mathrm{ha}^{-1}$ superficial & $6,50 \mathrm{~b}$ & $1,00 \mathrm{~b}$ & $23,00 \mathrm{~b}$ \\
\hline $40 \mathrm{t} \mathrm{ha}^{-1}$ incorporada & $7,50 \mathrm{~b}$ & $0,50 \mathrm{~b}$ & $11,00 \mathrm{bc}$ \\
\hline $50 \mathrm{t} \mathrm{ha}^{-1}$ superficial & $6,25 \mathrm{~b}$ & $0,00 \mathrm{~b}$ & $11,50 \mathrm{bc}$ \\
\hline $50 \mathrm{t} \mathrm{ha}^{-1}$ incorporada & $5,20 \mathrm{~b}$ & $0,25 \mathrm{~b}$ & $8,25 \mathrm{c}$ \\
\hline $80 \mathrm{t} \mathrm{ha}^{-1}$ superficial & $5,00 \mathrm{~b}$ & $0,00 \mathrm{~b}$ & $10,75 \mathrm{bc}$ \\
\hline $80 \mathrm{t} \mathrm{ha}^{-1}$ incorporada & $5,50 \mathrm{~b}$ & $0,00 \mathrm{~b}$ & $5,75 \mathrm{c}$ \\
\hline Testemunha & $12,50 \mathrm{a}$ & $12,25 \mathrm{a}$ & $63,50 \mathrm{a}$ \\
\hline CV & 26,99 & 40,53 & 35,02 \\
\hline DMS 5\% & 4,12 & 1,91 & 16,70 \\
\hline
\end{tabular}

Médias seguidas por letras iguais na coluna não diferem significativamente entre si pelo teste de Tukey a $5 \%$. 


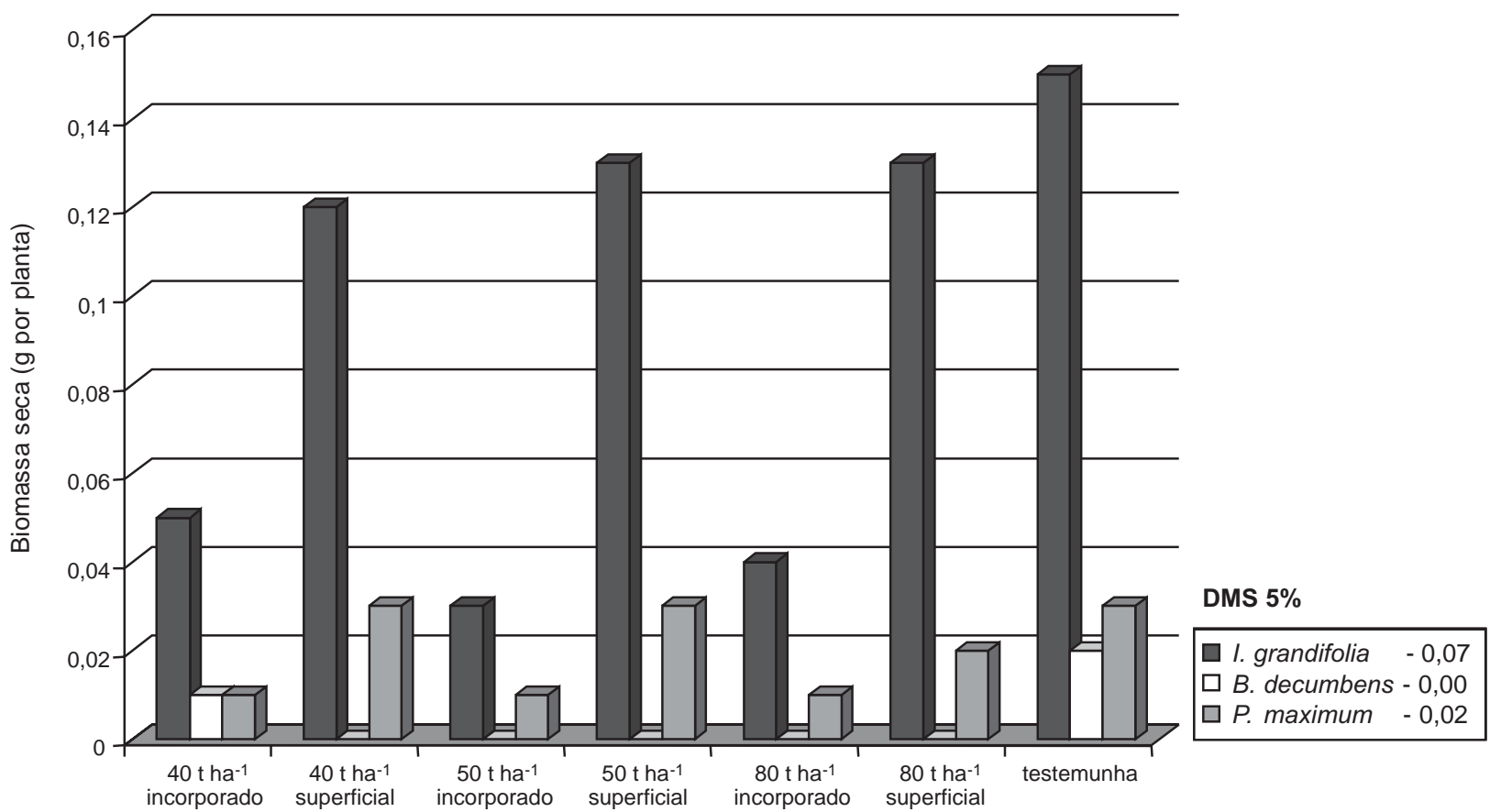

Figura 4 - Biomassa seca (g por planta) das plantas daninhas em diferentes tratamentos com palha de Pennisetum glaucum.

Tabela 6 - Número de plantas daninhas que emergiram nos tratamentos com diferentes adubos verdes e manejo

\begin{tabular}{|c|c|c|c|c|}
\hline \multirow{2}{*}{ Tratamento } & \multicolumn{4}{|c|}{ Número de plantas de I. grandifolia } \\
\hline & C. ensiformis & M. aterrima & C. juncea & P. glaucum \\
\hline $40 \mathrm{t} \mathrm{ha}^{-1}$ superficial & $7,25 \mathrm{~A}$ & $6,0 \mathrm{~B}$ & $6,25 \mathrm{~B}$ & $6,50 \mathrm{AB}$ \\
\hline $40 \mathrm{t} \mathrm{ha}^{-1}$ incorporada & $6,25 \mathrm{~B}$ & $3,0 \mathrm{C}$ & $14,0 \mathrm{~A}$ & $7,50 \mathrm{~B}$ \\
\hline $50 \mathrm{t} \mathrm{ha}^{-1}$ superficial & $7,0 \mathrm{~A}$ & $3,25 \mathrm{~B}$ & $4,75 \mathrm{~B}$ & $6,25 \mathrm{~A}$ \\
\hline $50 \mathrm{t} \mathrm{ha}^{-1}$ incorporada & $7,0 \mathrm{~B}$ & $4,0 \mathrm{C}$ & $12,0 \mathrm{~A}$ & $5,205 \mathrm{BC}$ \\
\hline $80 \mathrm{t} \mathrm{ha}^{-1}$ superficial & $2,50 \mathrm{~A}$ & $1,25 \mathrm{~A}$ & $2,0 \mathrm{~A}$ & $5,0 \mathrm{~A}$ \\
\hline $80 \mathrm{t} \mathrm{ha}^{-1}$ incorporada & $6,75 \mathrm{~A}$ & $1,25 \mathrm{C}$ & $3,25 \mathrm{~B}$ & $5,5 \mathrm{~A}$ \\
\hline $\mathrm{CV}$ & \multicolumn{4}{|c|}{19,39} \\
\hline DMS $5 \%$ & \multicolumn{4}{|c|}{0,81} \\
\hline \multirow{2}{*}{ Tratamento } & \multicolumn{4}{|c|}{ Número de plantas de $B$. decumbens } \\
\hline & C. ensiformis & M. aterrima & C. juncea & P. glaucum \\
\hline $40 \mathrm{t} \mathrm{ha}^{-1}$ superficial & $10,0 \mathrm{~A}$ & $3,0 \mathrm{~B}$ & $0,25 \mathrm{C}$ & $1,00 \mathrm{C}$ \\
\hline $40 \mathrm{t} \mathrm{ha}^{-1}$ incorporada & $8,0 \mathrm{~A}$ & $6,0 \mathrm{~B}$ & $5,25 \mathrm{C}$ & $0,50 \mathrm{C}$ \\
\hline $50 \mathrm{t} \mathrm{ha}^{-1}$ superficial & $8,25 \mathrm{~A}$ & $2,0 \mathrm{~B}$ & $0,75 \mathrm{C}$ & $0,00 \mathrm{C}$ \\
\hline $50 \mathrm{t} \mathrm{ha}^{-1}$ incorporada & $6,0 \mathrm{~A}$ & $6,0 \mathrm{~A}$ & $2,25 \mathrm{~B}$ & $0,25 \mathrm{C}$ \\
\hline $80 \mathrm{t} \mathrm{ha}^{-1}$ superficial & $1,0 \mathrm{~B}$ & $3,0 \mathrm{~A}$ & $0,25 \mathrm{C}$ & $0,00 \mathrm{C}$ \\
\hline $80 \mathrm{t} \mathrm{ha}^{-1}$ incorporada & $4,0 \mathrm{~A}$ & $0,0 \mathrm{~B}$ & $0,50 \mathrm{~B}$ & $0,00 \mathrm{~B}$ \\
\hline $\mathrm{CV}$ & \multicolumn{4}{|c|}{9,04} \\
\hline DMS 5\% & & & & \\
\hline \multirow{2}{*}{ Tratamento } & \multicolumn{4}{|c|}{ Número de plantas de $P$. maximum } \\
\hline & C. ensiformis & M. aterrima & C. juncea & P. glaucum \\
\hline $40 \mathrm{t} \mathrm{ha}^{-1}$ superficial & $147,0 \mathrm{~A}$ & $95,0 \mathrm{~B}$ & $82,0 \mathrm{~B}$ & $23,0 \mathrm{C}$ \\
\hline $40 \mathrm{t} \mathrm{ha}^{-1}$ incorporada & $173,0 \mathrm{~A}$ & $84,0 \mathrm{~B}$ & $57,0 \mathrm{cC}$ & $11,0 \mathrm{D}$ \\
\hline $50 \mathrm{t} \mathrm{ha}^{-1}$ superficial & $165,0 \mathrm{~A}$ & $48,0 \mathrm{~B}$ & $52,0 \mathrm{~B}$ & $11,50 \mathrm{C}$ \\
\hline $50 \mathrm{t} \mathrm{ha}^{-1}$ incorporada & $190,0 \mathrm{~A}$ & $54,0 \mathrm{C}$ & $66,0 \mathrm{~B}$ & $5,75 \mathrm{D}$ \\
\hline $80 \mathrm{t} \mathrm{ha}^{-1}$ superficial & $50,0 \mathrm{~A}$ & $20,0 \mathrm{~B}$ & $6,25 \mathrm{C}$ & $10,75 \mathrm{BC}$ \\
\hline $80 \mathrm{t} \mathrm{ha}^{-1}$ incorporada & $95,0 \mathrm{~A}$ & $44,0 \mathrm{~B}$ & $9,50 \mathrm{C}$ & $8,25 \mathrm{~B}$ \\
\hline $\mathrm{CV}$ & \multicolumn{4}{|c|}{10,87} \\
\hline DMS 5\% & \multicolumn{4}{|c|}{8,23} \\
\hline
\end{tabular}

Médias seguidas por letras iguais maiúsculas nas linhas, para cada espécie daninha, não diferem significativamente entre si pelo teste de Tukey a $5 \%$. 
De modo geral comparando o efeito de cada adubo verde sobre a emergência dessas espécies de plantas daninhas, observou-se que a leguminosa $M$. aterrima foi a mais eficiente na redução da emergência de $I$. grandifolia em todos os manejos (Tabela 6). Para B. decumbens e $P$. maximum, destacou-se $P$. glaucum seguido de $C$. juncea. Isso demonstra a importância de se estudar o efeito de diferentes coberturas sobre distintas espécies de plantas daninhas, sabendo-se que algumas plantas de coberturas verdes de leguminosas podem ser mais eficazes na supressão de espécies daninhas específicas, constituindo-se numa prática alternativa na composição do manejo integrado de plantas daninhas.

\section{LITERATURA CITADA}

ABBOUD, A. C. S.; DUQUE, F. F. Efeitos de materiais orgânicos e vermiculita sobre a sequência feijão-milho-feijão. Pesq. Agropec. Bras., v. 21, n. 3, p. 228-236, 1986.

ALMEIDA, F. S. Influência da cobertura morta na biologia do solo. A Granja, v. 4, n. 451, p. 52-67, 1985.

BURLE, M. L. et al. Caracterização das espécies de adubo verde. In: CARVALHO, A. M.; AMABILE, R. F. Cerrado: adubação verde. Planaltina: Embrapa cerrados, 2006. p. $71-142$.

CALEGARI, A. et al. Adubação verde no Sul do Brasil. 2.ed. Rio de Janeiro: ASPTA, 1993. 346 p.

CARSON, A. G. Improvement weed management in the draft animal-based production of early pearl millet in Gambia.

Trop. Pest Manag., v. 33, n. 2, p. 359-363, 1987.

CARVALHO, S. I. C. Caracterização dos efeitos alelopáticos de Brachiaria brizantha cv. Marandu no estabelecimento das plantas de Stylosanthes guianensis var. vulgaris cv. Bandeirante. 1993. 72 f. Dissertação (Mestrado em Zootecnia) - Universidade Federal de Viçosa, Viçosa, MG, 1993

CARVALHO, G. J.; FONTANETTI, A.; CANÇADO, C. T. Potencial alelopático do feijão-de-porco (Canavalia ensiformes) e da mucuna preta (Stilozobium aterrimum) no controle da tiririca (Cyperus rotundus). Ci. Agrotec., v. 26, n. 3, p. 647-651, 2002.

CORREIA, N. M.; DURIGAN, J. C. Emergência de plantas daninhas em solo coberto com palha de cana-de-açúcar. Planta Daninha, v. 22, n. 1, p. 11-17, 2004.

ERASMO, E.A.L. et al. Potencial de espécies utilizadas como adubo verde no manejo integrado de plantas daninhas. Planta Daninha, v. 22, n. 3, p. 337-342, 2004.
GOMES, J. C.; LEAL, E. C. Plantas daninhas na cultura da mandioca. Cruz das Almas: 2003. (Sistemas de Produção/ Embrapa, 11)

GUIMARÃES, S. C.; SOUZA, I. F.; PINHO, E. V. R. V. Emergência de Tridax procumbens em função da profundidade de semeadura, do conteúdo de argila no substrato e da incidência de luz na semente. Planta Daninha, v. 20, n. 3, p. 413-419, 2002.

LEIGH, J. H.; HALSALL, D. M.; HOLGATE, M. D. The role of allelopathy in legume decline in pasture. I. Effects of pasture and crop residue on germination and survival of subterranean clover in the field and nursery. Austr. J. Agric. Res., v. 46, n. 1, p. 179-188, 1995.

MARTINS, D. et al. Emergência em campo de dicotiledôneas infestantes em solo coberto com palha de cana-de-açúcar. Planta Daninha, v. 17, n. 1, p. 151-161, 1999.

MEDEIROS, A. R. M.; CASTRO, L. A. S.; LUCCHESI, A A. Efeitos alelopáticos de algumas leguminosas e gramíneas sobre a flora invasora. An.. ESALQ, v. 47, n. 1, p. 1-10, 1990 .

PEREIRA, R. V.; SILVA, A. Controle alelopático de tiririca por mucuna e feijão-de-porco. Goiânia: UFG/CNPq, 1989. 3 p. Projeto de pesquisa.

PIRAI sementes. Disponível em: <www.pirai.com.br> Acesso em: 2 abr. 2008.

PITELLI, R. A.; PITELLI, R. L C. M. Biologia e ecofisiologia das plantas daninhas. In: VARGAS, L.; ROMAM, E. S. (Eds.). Manual de manejo e controle de plantas daninhas. Bento Gonçalves: Embrapa Uva e Vinho, 2004. p. 29-56.

PITELLI, R. A.; DURIGAN, J. C. Ecologia das plantas daninhas no sistema plantio direto. In: ROSSELLO, R. D. Siembra directa en el cono sur. Montevideo: PROCISUR, 2001. p. 203-210.

PITOL, C. A cultura da aveia e sua importância para o MS. Maracaju: COTRIJÚ, 1986. 35 p. (Boletim Técnico, 1)

RICE, E. L. Allelopathy. 2.ed. New York: Academic, 1984. $422 \mathrm{p}$.

RODRIGUES, L. R. A.; ALMEIDA, A. R. P.; RODRIGUES, T. J. D. Alelopatia em forrageiras e pastagens. In: SIMPÓSIO SOBRE ECOSSISTEMA DE PASTAGENS, 1993, Jaboticabal. Anais... Jaboticabal: FUNEP, 1993. p. 100-129.

SEVERINO, F. J.; CRISTOFFOLETI, P. J. Efeitos de quantidades de fitomassa de adubos verdes na supressão de plantas daninhas. Planta Daninha, v. 19, n. 2, p. 223-228, 2001.p 
SILVA, Z. L. Alelopatia e defesa em plantas. B. Geográfico, v. 36, n. $258-259$, p. 90-96, 1978.

SINIGAGLIA, C . et al. Alelopatia e defesa em plantas.

B. Geográfico, v. 36, n. 258-259, p. 90-96, 1978.

SOUZA, I. F. Alelopatia de plantas daninhas. Inf. Agropec., v. 13, n. 150, p. $75-78,1988$.

SOUZA FILHO, A. P. S. Atividade potencialmente alelopática de extratos brutos e hidroalcoolicos de feijão-deporco (Canavalia ensiformis). Planta Daninha, v. 20, n. 3, p. 357-364, 2002.
TREZZI, M. M.; VIDAL, R. A. Potencial de utilização de cobertura vegetal de sorgo e milheto na supressao de plantas daninhas em condição de campo: II Efeitos da cobertura morta. Planta Daninha, v. 22, n. 1, p. 1-10, 2004.

WEIDENHAMER, J. D. Distinguishing resource competition and chemical interference: overcoming the methodological impasse. Agron. J., v. 88, n. 6, p. 866-875, 1996.

WUTKE, E. B. Adubação verde: manejo da fitomassa e espécies utilizadas no Estado de São Paulo. Campinas: IAC, 1993. 37 p. (IAC. Documentos, 35). 